\title{
POTENCIAL ALELOPÁTICO DO CAPIM-ANNONI-2 (Eragrostis plana Nees) NA GERMINAÇÃO DE SEMENTES DE GRAMÍNEAS PERENES ESTIVAIS ${ }^{1}$
}

\author{
NADILSON R. FERREIRA², RENATO B. DE MEDEIROS ${ }^{3}$, GERALDO LUIZ G. SOARES ${ }^{4}$
}

\begin{abstract}
RESUMO - Das estratégias adotadas pelas plantas invasoras para dominância em comunidades vegetais a liberação de aleloquímicos se sobressai. Estes compostos encontram-se em qualquer parte vegetal, principalmente em exsudatos de raízes, folhas e seus degradados sendo liberados no ambiente através de emanações voláteis ou solúveis, translocados em água. O capim-annoni-2, Eragrostis plana Nees, é uma Poaceae exótica, invasora de pastagens e com potencial alelopático. Para testar este efeito coletaram-se caules e folhas da parte mediana da planta de capim-annoni-2, que foram cortados em pedaços de $0,5 \mathrm{~cm}$ e dispostos em três níveis de cobertura $0 \%, 50 \%$ e $100 \%$ em caixas gerbox, usando papel germitest como substrato sobre o material picado de capim-annoni- 2 . Foram colocadas para germinar 100 sementes das espécies: Paspalum notatum Flüggé, $P$. regnellii Mez, Megathyrsus maximus B. K. Simon e S. W. L. Jacobs, Setaria sphacelata (Schumach) Staff e C. E. Hubb ex Chipp e Lactuca sativa L. como testemunha. O delineamento foi em blocos casualizados com quatro repetições. Observou-se o efeito alelopático na germinação das sementes após o início da decomposição do tecido vegetal do capim-annoni-2. Sementes com rápida germinação, como as de M. maximus e P. regnellii bem como a L. sativa, escaparam do efeito alelopático. As espécies mais prejudicadas nos seus processos germinativos foram o P. notatum e S.sphacelata. O dano à germinação foi proporcional ao gradiente crescente do nível de cobertura do capim-annoni-2 com exceção do $P$. regnellii que apresentou no nível de 50\% de cobertura do capim-annoni-2, aumento na germinação, porém com queda significativa da mesma no nível de $100 \%$ de cobertura. $\mathrm{O}$ efeito alelopático do capim-annoni-2 se dá durante a decomposição dos seus tecidos vegetais. Sementes com germinação precoce escapam destes efeitos. A germinação tardia de P. notatum e S. sphacelata as expôs ao efeito alelopático do capim-annoni-2. A germinação de $P$. regnellii é estimulada no nível de cobertura com capim-annoni-2 de 50\%, contudo, na cobertura máxima há queda significativa na germinação de suas sementes.
\end{abstract}

Termos para indexação: espécie invasora, exsudato, níveis de cobertura, decomposição, germinação.

\section{ALELOPATHIC POTENTIAL OF CAPIM-ANNONI-2 (Eragrsotis plana Nees) ON THE SEED GERMINATION OF SUMMER PERENNIAL GRASSES}

\begin{abstract}
Among plant strategies to invade and dominate the plant community, the release of alelochemicals is prominent. These compounds are present in all plant parts, principally, in root exudates, leaves and their degraded parts. They are released in the environment through volatile or soluble emanations, translocated in water. Capim-annoni-2 is an invasive exotic Poaceae of rangeland vegetation with allelopatic potential. To test this effect, plant structures from the mid part of capimannoni- 2 were collected and cut in small pieces of $0.5 \mathrm{~cm}$ and placed in three covering levels of 0 , 50 and $100 \%$ in gerboxes covered with germitest blotters over the cut material. A hundred seeds of Paspalum notatum Flüggé, P. regnellii Mez, Megathyrsus maximus B. K. Simon and S. W. L.
\end{abstract}

\footnotetext{
${ }^{1}$ Submetido em10/01/2007. Aceito para publicação em 24/12/2007.

${ }^{2}$ Eng. Agrônomo, MSc., Departamento de Plantas Forrageiras e 'Eng. Agrônomo, MSc., Departamento de Plantas Forrageiras $\mathrm{PhD}$. Dep. Plantas Forrageiras e Agrometeorologia, Fac. Agronomia,
}

UFRGS, Av. Bento Gonçalves, 7712, CEP: 91540-000, Porto Alegre - RS. renato.medeiros@ufrgs.br. Professor Adjunto, PhD. Dep. De Botânica, UFRGS, Porto Alegre, RS; geraldo.soares@ufrgs.br 


\begin{abstract}
Jacobs, Setaria sphacelata (Schumach) Staff and C. E. Hubb ex Chipp and Lactuca sativa L., were placed to germinate as controls. A randomized complete block design was used with four replications. The allelopatic effect was observed on the seed germination after the beginning of capim-annoni-2 plant tissue decomposition. Seeds with high speed germination, such as M. maximus and P. reginelli as well as L. sativa, escaped the allelopatic effect. The most damaged species in their germination course were $P$. notatum e $S$. sphacelata. The germination injury was proportional to the gradient increase of the capim-annoni-2 covering tissue with the exception of $P$. reginelli which showed, at $50 \%$ capim-annoni- 2 covering level, an increase in germination, but at $100 \%$ level there was a significant germination reduction. The capim-annoni-2 allelopathic effects occur during plant tissue decomposition. Seeds with precocious germination escape these effects. The late germination of $P$. notatum and $S$. sphacelata exposed them to the capim-annoni-2 allelopathic effects. $P$. reginelli germination was stimulated at $50 \%$ covering level to capim-annoni-2, but at maximum level there was a significant germination decrease in its seeds.
\end{abstract}

Index terms: invasive species, exudate, covering levels, decomposition, germination.

\section{INTRODUÇÃO}

Uma das estratégias utilizadas pelas plantas invasoras para competir e dominar em comunidades vegetais é a liberação de aleloquímicos, produtos do metabolismo secundário, tendo como matérias-prima as substâncias originadas no metabolismo primário (Lacher, 2000). A alelopatia é o efeito de uma planta sobre outra, através da liberação de substâncias no ambiente que apresentam ação direta ou indireta sobre espécies vizinhas, incluindo-se interações intra e inter plantas e microorganismos, podendo haver domínio de uma espécie sobre outra que apresenta susceptibilidade no ambiente compartilhado (Rice et al., 1984). Essas substâncias encontram-se em todas as partes da planta, principalmente nas raízes e folhas (Rodrigues e Weston, citado por Rezende, 2003), são liberadas no ambiente por emanações voláteis ou compostos solúveis em água. Chega ao solo pelo exsudato de raízes, liberação direta da parte aérea da planta e carreada pela água, bem como através da decomposição de restos vegetais. Estes produtos agem na fisiologia das plantas, principalmente sobre a divisão, alongamento e ultraestrutura celular, interferem nos mecanismos hormonais de indução de crescimento, na permeabilidade das membranas celulares, abertura estomática, fotossíntese, respiração, síntese protéica, metabolismo de lipídios e dos ácidos graxos (Rice, 1984). O estresse causado na planta alvo é semelhante ao ataque por vírus (Bassi, citado por Rizvi, 1992) ou estresse provocado por metais pesados (Wierzbicka, citado por Rizvi, 1992).

O capim-annoni-2, Eragrostis plana Nees, é uma Poaceae tropical, perene, estival, exótica, com origem na África, introduzida acidentalmente no Brasil como contaminante de sementes importadas, na década de 1950.
Possui atributos de planta invasora tais como a rejeição pelos animais, rápida crescimento, longa fase reprodutiva, presença de alelopatia (Coelho, 1984) e banco de sementes do solo persistente (Medeiros et al, 2004a). Supõe-se que seus os efeitos alelopáticas prejudicam a germinação de sementes de diversas espécies nativas e exóticas, fato que pode estar contribuindo para a expansão do capim-annoni-2 sobre os campos nativos no Rio Grande do Sul (RS). Estimase a área atual invadida no RS em torno de um milhão de hectares (Medeiros et al., 2004b), o que significa expressivos prejuízos ambientais, econômicos e sociais ao Estado.

O presente trabalho justificou-se em função da demanda de respostas a observações realizadas quanto à diminuição da germinação de sementes introduzidas de espécies de Poaceae nativas e exóticas, em um projeto de pesquisa de controle ecológico de focos dispersores de capim-anonni-2 as margens de rodovias (Ferreira, 2006). O objetivo foi avaliar o efeito alelopático de plantas de capim-annoni-2 sobre a germinação de sementes de gramíneas nativas e exóticas.

\section{MATERIAL E MÉTODOS}

No estudo, utilizou-se estruturas vegetativas de caules e folhas coletadas da porção mediana de plantas adultas de capim-annoni-2, às margens da estrada vicinal na Fazenda São Lucas, Km 197 da BR 290, município de Rio Pardo, Rio Grande do Sul, na região eco-climática da Depressão Central, caracterizada por uma vegetação campestre condicionada pelo frio do inverno e déficit hídrico no verão. Seus solos têm origem nas rochas areníticas (Fortes, 1959) e são classificados como argissolo vermelho distrófico latossólico - PVd4 (Streck et al., 2002). De acordo com a classificação 
de Köeppen o clima da região é caracterizado como tipo Cfa, subtropical úmido com chuvas bem distribuídas durante o ano e com temperatura média do mês mais quente superior a $22^{\circ} \mathrm{C}$.

Os testes do efeito alelopático foram conduzidos no Laboratório de Sementes do Departamento de Plantas Forrageiras e Agrometeorologia da UFRGS. As sementes de espécies nativas testadas foram: Paspalum notatum Flüggé ecótipo André da Rocha (grama-de-forquilha), colhidas no campo da área experimental da UFRGS; Paspalum regnellii $\mathrm{Mez}$ (macega-do-banhado), fornecidas por produtor de sementes de Pantano Grande, Faz. Alqueire. As exóticas foram: Setaria sphacelata (Schumach) Staff e C. E. Hubb ex Chipp (capim-kazungula) e Megathyrsus maximus B. K. Simon e S. W. L. Jacobs (capim-tanzânia), fornecidas pela empresa Matsuda de São Paulo. Como espécie testemunha foi usada Lactuca sativa L. (alface var. Crespa Grand Rapids), adquirida no comércio local. As sementes de todas as espécies foram colhidas no ano de 2004. As sementes e as partes vegetais do capim-anonni-2 usadas foram desinfetadas com hipoclorito de sódio a $2 \%$ por 15 minutos, com posterior enxágüe com água destilada. Em caixas gerbox, depositaram-se os fragmentos verdes de folhas e colmos de capim-annoni-2, com dimensões de $0,5 \mathrm{~cm}$, em três níveis de cobertura $(0 \%, 50 \%$ e $100 \%)$, correspondendo respectivamente à ausência, $6,0 \mathrm{~g}$ e $12,0 \mathrm{~g}$ de capim-annoni-2. O nível de $100 \%$ de cobertura equivale à área do fundo da caixa gerbox completamente preenchida com as estruturas picotadas sem sobreposição dos tecidos. No nível de 50\% a distribuição do material no fundo da caixa se deu de forma esparsa e homogênia. Posteriormente, o material foi coberto com uma folha de papel germitest umedecida com água destilada. As caixas com níveis de $50 \%$ e $100 \%$ de cobertura foram preparadas três dias antes, com o intuito de permitir a absorção do princípio alelopático pelo papel. A proposta desta metodologia foi aproximar-se das condições de campo, onde o processo de decomposição do tecido vegetal se dá em meio aeróbico. Utilizaram-se 100 sementes de cada espécie, distribuídas equidistantemente sobre o papel umedecido. As caixas foram mantidas em germinador a $25^{\circ} \mathrm{C}$, sem luz adicional por oito horas e a $30^{\circ} \mathrm{C}$ na fase clara de 16 horas, conforme as Regras de Análise de Sementes (Ministério da Agricultura, 1992). Consideraram-se sementes germinadas aquelas com raiz primária com tamanho igual ou superior a dois milímetros. A observação foi concluída em um período de 26 dias, realizando-se leituras diárias, tendo início em 21 de dezembro de 2005 e término em 15 de janeiro de 2006. Calculou-se o índice de velocidade de germinação (IVG) anotando-se diariamente, no mesmo horário, o número de plântulas germinadas. Ao final somou-se o número de sementes germinadas por dia, dividindo-se pelo respectivo número de dias contados a partir da semeadura de acordo com a fórmula: $\mathrm{IVG}=\left(\mathrm{G}_{1} / \mathrm{N}_{1}\right)+\left(\mathrm{G}_{2} / \mathrm{N}_{2}\right)+\ldots+\left(\mathrm{G}_{\mathrm{n}} / \mathrm{N}_{\mathrm{n}}\right)$, onde " $\mathrm{G}$ " é o número de sementes germinadas e " $\mathrm{N}$ " é o número de dias da semeadura à $1^{\mathrm{a}}, 2^{\mathrm{a}}, \ldots$, enésima avaliação (Maguire, 1962). A reposição de água, para evitar o ressecamento do substrato, foi feita pelas paredes da caixa gerbox, evitandose a pulverização direta da água destilada sobre as sementes e substrato com conseqüente lavagem dos mesmos e carreamento temporário dos compostos bioativos para o fundo da caixa com possível alteração dos resultados.

Antes da condução da análise estatística foi realizado o teste de Hartley ou da razão máxima para averiguar a homocedasticidade (Banzatto e Kronka, 1992), com conseqüente necessidade de transformação dos dados, adotando-se a transformação angular arco-seno. Além disto, em função de variações nas taxas de germinação entre espécies, originadas de diferenças na qualidade fisiológicas das sementes e também possíveis características intrínsecas das mesmas, os dados primários de germinação das sementes tratadas com os três níveis de cobertura com o capim-annoni-2 foram normalizados, de acordo com a equação: $y=100 * \mathrm{~g} / \mathrm{G}$; onde y é a germinação original normalizada; g as germinações originais de cada espécie; e G a germinação original máxima de cada espécie (Hopkinson, 1983). O experimento foi conduzido no delineamento blocos casualizados com quatro repetições, no esquema fatorial, combinando cinco espécies com três níveis de cobertura resultando em 15 tratamentos. Foi realizado o desdobramento do grau de liberdade do fator tratamento para o estudo do efeito de cobertura. As médias dos tratamentos foram comparadas pelo teste de Tukey a 5\% de probabilidade.

\section{RESULTADOS E DISCUSSÃO}

Houve redução na germinação das sementes com o aumento do nível de cobertura com capim-annoni-2 (Tabela 1), excetuando-se a macega-do-banhado que no nível de $50 \%$ de cobertura teve a germinação estimulada, assumindo o padrão das outras espécies no limiar de 100\%. Um composto aleloquímico pode ter seu efeito inibitório ou estimulante, dependendo de sua concentração no meio ambiente (Rice, 1979). A queda na germinação foi pequena no capim-tanzânia e principalmente na testemunha. O capim-kazungula e a grama-de-forquilha foram as espécies mais afetadas. É possível que o baixo vigor ou presença de 
mecanismos atenuadores tenham dificultado a germinação do capim-kazungula (Strickland, 1971) assim como da grama-de-forquilha (Maeda e Pereira, 1997), causando atraso na germinação destas espécies contribuindo para que as mesmas tenham apresentado significância quanto aos efeitos alelopáticos. As curvas de germinação acumulada das espécies apresentadas na Figura 1A, B, C, D e E, indicam que a resposta de cada espécie aos três níveis de cobertura são semelhantes e proporcionais aos valores observados na Tabela 1.

FIGURA 1. Efeitos de três níveis de cobertura de exsudato de resíduos de folhas e caules de capim-annoni-2 $(0=0 \%, 1$ $=50 \%$ e $2=100 \%$ ) sobre a germinação acumulada de sementes de A: grama-de-forquilha - PN (PN0, PN1 e PN2); B: capim-kazungula - SS (SS0, SS1 e SS2); C: capim-tanzânia - MM (MM0, MM1 e MM2); D: macega-do-banhado - PR, (PR0, PR0 e PR0) e E: alface, - LS (LS0, LS1 e LS2). UFRGS, Porto Alegre, 2006.

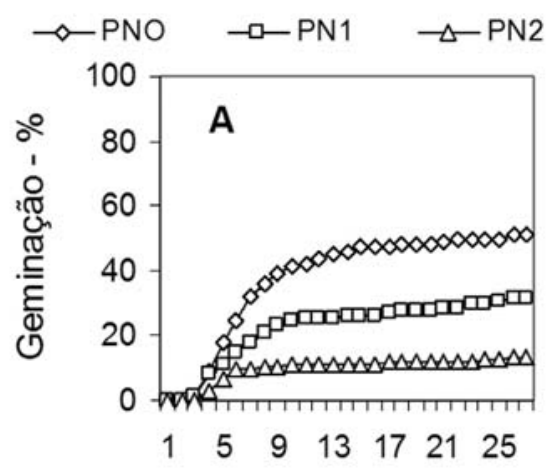

Dias de contagem

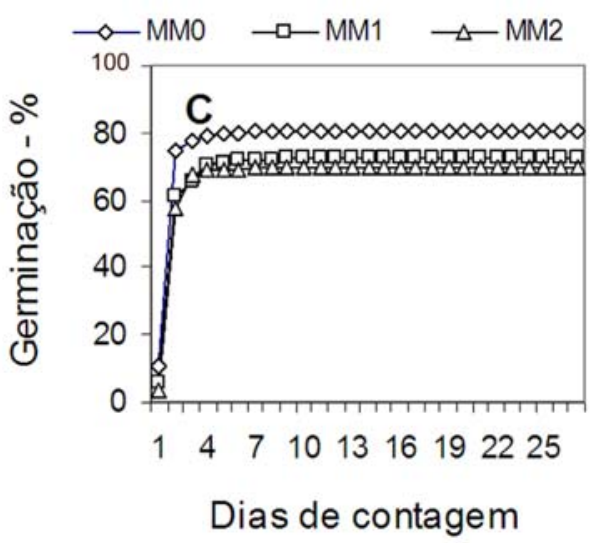

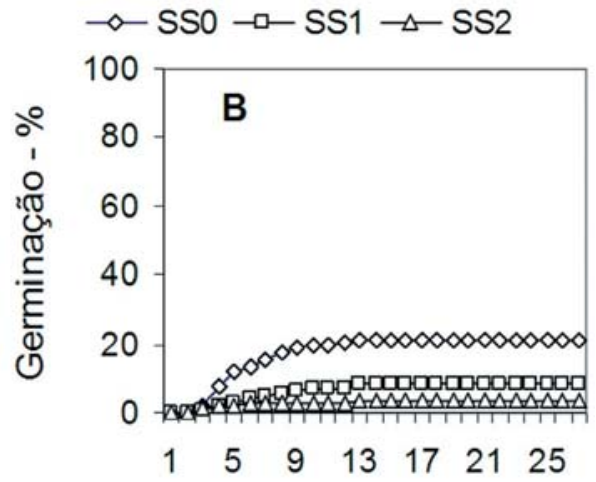

Dias de contagem

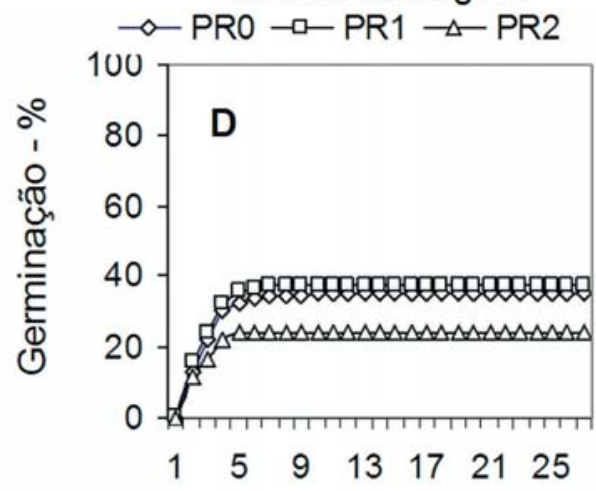

Dias de contagem

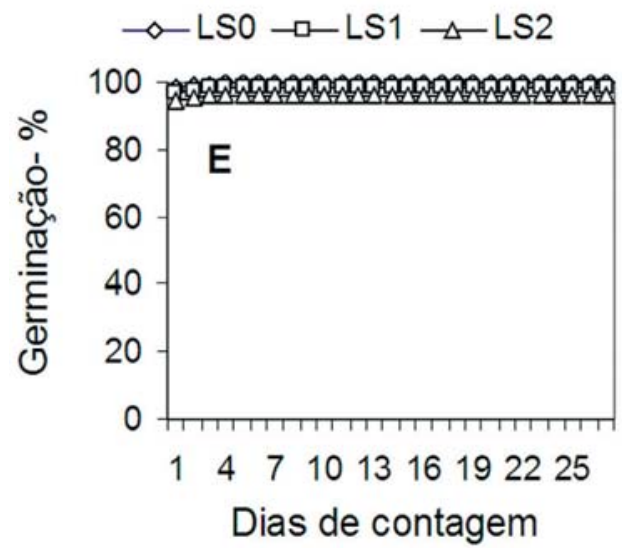


TABELA 1. Germinação (\%) de sementes de espécies forrageiras tropicais e alface, expostas ao efeito do exsudato de folhas e colmos da planta de capim-annoni-2 em três níveis de cobertura. UFRGS, Porto Alegre, RS, 2006.

\begin{tabular}{|c|c|c|c|c|}
\hline \multicolumn{5}{|c|}{ Níveis de cobertura (\%) } \\
\hline Espécies & 0 & 50 & 100 & Médias \\
\hline Grama-de-forquilha & $100,0 \mathrm{a}$ & $59,8 \mathrm{~b}$ & $24,1 \mathrm{c}$ & 61,3 \\
\hline Capim-kazungula & $100,0 \mathrm{a}$ & $39,9 \mathrm{~b}$ & $14,4 \mathrm{~b}$ & 51,4 \\
\hline Capim-tanzânia & $100,0 \mathrm{a}$ & 89,8 a & $85,7 \mathrm{a}$ & 91,8 \\
\hline Macega-do-banhado & 94,6 a & $100,0 \mathrm{a}$ & $63,0 \mathrm{~b}$ & 85,9 \\
\hline Alface & $100,0 \mathrm{a}$ & $98,2 \mathrm{a}$ & $96,2 \mathrm{a}$ & 98,1 \\
\hline Médias & 98,9 & 77,5 & 56,7 & \\
\hline
\end{tabular}

Os valores de IVG refletem as trajetórias descritas na Figura 1 e apresentam uma relação de proporcionalidade com as taxas de germinação da Tabela 1. Os IVG oscilaram entre valores elevados $(97,5)$ para alface no tratamento de $50 \%$ de cobertura e baixos $(0,8)$ para capim-kazungula na cobertura de $100 \%$. A germinação das sementes da testemunha (alface) ocorreu praticamente em um dia, enquanto que as de capimkazungula, com taxa de germinação mais lenta, necessitaram de 10 dias para atingir a germinação máxima. As porcentagens de germinação das sementes de capim-tanzânia e de alface apresentaram variação muito discreta em relação aos três níveis de cobertura, não ocorrendo diferença significativa $(p<0,05)$ (Tabela 1). As sementes de alface germinaram no primeiro dia após o semeio, enquanto que as sementes de capim-tanzânia, nos primeiros dois dias (Figura 1). Os altos valores de IVG confirmam que as duas espécies foram as mais rápidas a germinarem, atingindo valores médios de 97,2 e 38,2 para alface e capim-tanzânia, respectivamente (Tabela 2). Este período curto de germinação, especialmente no caso da alface, pode ser uma indicação de que estas espécies têm a oportunidade de escaparem da fase inicial de decomposição do tecido vegetal do capim-annoni-2, e da conseqüente liberação do princípio alelopático e seu efeito prejudicial sobre a germinação das sementes, conforme descrito por Coelho (1984).

TABELA 2. Índice de velocidade de germinação de sementes de gramíneas tropicais e alface, expostas a ao efeito de exsudatos de folhas e colmos da planta de capim-annoni-2 em três níveis de cobertura. UFRGS, Porto Alegre, RS, 2006.

\begin{tabular}{lcccc}
\hline & \multicolumn{3}{c}{ Níveis de cobertura (\%) } & Médias \\
\cline { 2 - 4 } \multicolumn{1}{c}{ Espécies } & 0 & 50 & 100 & 5,0 \\
Grama-de-forquilha & $8,0 \mathrm{a}$ & $4,8 \mathrm{ab}$ & $2,2 \mathrm{~b}$ & 2,0 \\
Capim-kazungula & $4,0 \mathrm{a}$ & $1,4 \mathrm{a}$ & $0,8 \mathrm{a}$ & 38,2 \\
Capim-tanzânia & $44,2 \mathrm{a}$ & $36,3 \mathrm{~b}$ & $34,0 \mathrm{~b}$ & 11,8 \\
Macega-do-banhado & $12,5 \mathrm{a}$ & $14,0 \mathrm{a}$ & $9,1 \mathrm{~b}$ & 97,2 \\
Alface & $99,2 \mathrm{a}$ & $97,5 \mathrm{a}$ & $95,5 \mathrm{a}$ & \\
\hline \multicolumn{1}{c}{ Médias } & 33,4 & 30,8 & 28,2 & \\
\hline
\end{tabular}

Letra igual nas linhas indica que as médias não diferem entre si pelo teste de Tukey $\mathrm{p}(>0,05)$ 
Observa-se nas porcentagens de germinação das sementes de macega-do-banhado diferença significativa no nível de $100 \%$ quando comparados com os outros dois níveis $(\mathrm{p}<0,05)$ (Tabela 1). As sementes no nível de cobertura de $100 \%$ apresentaram menor taxa de germinação do que as dos níveis $0 \%$ e $50 \%$ de cobertura de capim-annoni-2. A germinação desta espécie estendeu-se até o sétimo dia (Figura 1), apresentando o terceiro maior IVG médio (Tabela 2). É possível que esta demora na germinação, em relação à testemunha alface e ao capim-tanzânia, tenha exposto estas sementes ao efeito alelopático, pelo menos no tratamento $100 \%$ de cobertura, quando se verificou a menor taxa de germinação $(63,0 \%)$ e o menor IVG $(9,1)$. Este efeito na germinação e no desenvolvimento de plântulas, ocasionado por exsudatos de partes da planta de capim-annoni-2, foi verificado por Coelho (1984) em trevo-branco (Trifolium repens L.) e cornichão (Lotus corniculatus L.). Nesses estudos, Coelho (1984) considerou que existe a possibilidade de o capim-annoni-2 exercer atividade alelopática inter e intra-específica que são prejudiciais ao desenvolvimento de diversas espécies, inclusive a germinação e o crescimento de sua própria plântula. Visser (1966) relata que, em espécies do gênero Eragrostis, no qual se encontra o capimannoni-2, foi detectada a liberação de grande número de aminoácidos, compostos fenólicos e ácido glutâmico, todas com reconhecido potencial alelopático.

A grama-de-forquilha apresentou significância $(\mathrm{p}<$ $0,05)$ quando comparado o nível sem capim-annoni-2 com os níveis de 50 e $100 \%$, e também entre os níveis 50 e $100 \%$ (Tabela 1). Verifica-se, neste caso, que quanto maior o nível de cobertura, menor a germinação das sementes (Tabela 1). O IVG diminui na mesma proporção, indicando que a grama-de-forquilha é sensível ao efeito alelopático, especialmente no tratamento de $100 \%$ de cobertura, quando o IVG é reduzido para 24,1. A analise desses resultados permite especular que o capim-annoni-2 pode representar uma forte ameaça à grama-de-forquilha, uma das espécies nativas mais importante do Bioma Pampa, pela sua abundância e valor nutritivo. Este fato já foi observado por Ferreira (2006), em estudos de restauração de acostamento de rodovias invadidas por capim-annoni-2, onde se semeou três espécies nativas (Paspalum urvillei L.; Paspalum regnellii Mez.; e Paspalum notatum Flüggé ecótipo André da Rocha). Neste trabalho, o autor acompanhou a dinâmica da germinação fazendo contagem de plântulas de grama-deforquilha. Verificou também que as sementes germinaram e desenvolveram plântulas na primavera, mas duas semanas após desapareceram, enquanto as plântulas das duas outras espécies se desenvolveram normalmente.

No capim-kazungula, a germinação foi inversamente proporcional ao gradiente crescente do nível de cobertura com capim-annoni-2. Observou-se significância $(p<0,05)$ na germinação das sementes quando comparado ausência de capim-annoni-2 com o nível de 50 e $100 \%$ de cobertura. Entre os níveis de 50 e 100\% não houve significância. (Tabela 1). IVG do capim-kazungula não foi significativo entre os níveis de cobertura (Tabela 2). Observa-se na Figura 1B que a taxa de germinação de capim-kazungula foi a mais lenta entre as espécies estudadas, levando em torno de 10 dias para atingir valores máximos. A semelhança do que ocorreu com a grama-de-forquilha, a espécie capim-kazungula, pelo fato de germinar lentamente e também ser sensível ao efeito alelopático de exsudatos de capim-annoni-2, teve a sua taxa de germinação prejudicada tanto no menor como no maior nível de cobertura (Tabela 1).

A análise dos resultados permite inferir que, de um modo geral, as sementes viáveis de alface e de capim-tanzânia germinaram praticamente antes do início da decomposição aeróbica dos tecidos de capim-annoni-2. Neste caso, em função de germinarem em apenas três dias após o plantio, escaparam do efeito alelopático, mesmo sendo a alface muito sensível a este fator, pois os efeitos da alelopatia ainda não tinham sido ativados. As sementes de capim-kazangula e grama-de-forquilha, ao contrário, ao atrasarem o início da germinação, ficaram expostas aos efeitos alelopáticos dos tecidos de capim-annoni-2, ocasionando prejuízos nas taxas de germinação.

Ocorreu sinergismo na germinação da macega-dobanhado, no nível de 50\% de cobertura com capim-annoni-2. Mais sementes germinaram do que na ausência do princípio alelopático, quebrando o padrão esperado. Tal fenômeno é observado em muitas interações alelopáticas, onde a baixa concentração do composto bioativo pode estimular o desenvolvimento das estruturas vegetais, sendo inibidas em concentrações mais elevadas (Rice, 1984). A significância só foi observada no nível de $100 \%$ quando comparada com as demais coberturas (Tabela 1).

Emgeral,emcondiçõesdecampo,osefeitosaleloquímicos dos resíduos de plantas declinam em um período de duas a três semanas após o processo de decomposição (Kimber et al., citado por Liebman, 2001), em função dos fatores edafoclimáticos.

\section{CONCLUSÕES}

O efeito alelopático se manifesta no processo de 
decomposição dos tecidos vegetais do capim-annoni-2;

Sementes com germinação rápida como as das forrageiras capim-tanzânia e de macega-do-banhado, bem como a alface, escapam do efeito alelopático;

A demora das sementes de grama-de-forquilha e capimkazungula para iniciarem a germinação as expôs ao efeito alelopático das estruturas de capim-annoni-2;

A germinação das sementes de macega-do-banhado é estimulada na presença de valor intermediário (50\%) de cobertura de partes da planta de capim-annoni-2, mas prejudicada na cobertura máxima $(100 \%)$.

\section{AGRADECIMENTOS}

À Fazenda São Lucas no município de Rio Pardo, por ter facultado suas estruturas e campo; ao Sindicato Rural de Rio Pardo pelo apoio financeiro; ao Departamento de Plantas Forrageiras e Agrometeorologia da URFGS, pelo uso do laboratório de sementes; ao Prof. Dr. João Carlos de Saibro pela sua contribuição na leitura do artigo e a CAPES, Coordenação de Aperfeiçoamento de Pessoal de Nível Superior, pela concessão da bolsa de mestrado.

\section{REFERÊNCIAS}

BANZATTO, D. A.; KRONKA, S. N. Experimentação agrícola. Jaboticabal: FUNEP, 1992. 247p.

BOLDRINI, I. I. Campos do Rio Grande do Sul: caracterização fisionômica e problemática ocupacional. Porto Alegre: Instituto de Biociências, Universidade Federal do Rio Grande do Sul, 1997. p.1-39. n.56

BRASIL. Ministério da Agricultura e da Reforma Agrária. Regras para análise de sementes. Brasília, DF: SNDA/ DNDV/CLAV, 1992. 365p.

COELHO, R. W. Efeito alelopático em Eragrostis plana. Agropecuário Clima Temperado, Pelotas, v.3, n.1, p.69$74,2000$.

COELHO, R. W. Substâncias fitotóxicas presentes no CapimAnnoni-2. Pesquisa Agropecuária Brasileira, Brasília, DF, v.21, n.3, p. 255-263, 1986.

HARBORNE, J. B. Introduction to ecological biochemistry. Whiteknights: Academic Press University of Reading, 1994. $318 \mathrm{p}$.

HIERRO, J. L.; CALLAWAY, R. M. Allelopathy and exotic plant invasion. Plant and Soil, v.256, p. 29-39, 2003.
HOPKINSON, J. M. Perdas na produção de sementes de gramíneas. In. MEDEIROS, R.B.; NABINGER, C.; SAIBRO, J.C. de (Ed.). Produção e tecnologia de sementes de forrageiras tropicais e subtropicais. Ijuí: COTRIJUÍ, 1983. p.8-28.

JACOBI, U. S.; FLECK, N. G. Avaliação do potencial alelopático de genótipos de aveia no inicio do ciclo. Pesquisa Agropecuária Brasileira, Brasília, DF, v.35, n.1, p. 11-19, 2000 .

LARCHER, W. Ecofisiologia vegetal. São Carlos: RiMa, 2000. 531p.

LIEBMAN, M.; MOHLER, C. L.; STAVER, C. P. Ecological management of agricultural weeds. Cambridge: Cambridge University Press, 2001. 532p.

MAEDA, J.A; PEREIRA, M.F.D.A Caracterização, beneficiamento e germinação de Paspalum notatum Flüggé. Revista Brasileira de Sementes, Brasília, DF, v.19, n.1, p.100-105, 1997.

MAGUIRE, J. D.; Speed of germination - aid in selection and evaluation for seedling emergence and vigor. Crop Science, Madison, v.2, n.1, p. 176-177, 1962.

MEDEIROS, R. B.; FOCHT, T.; FERREIRA, N. R.; BRACK, S. C. F. Longevidade de sementes de Eragrostis plana Nees em um solo de campo natural. In: REUNIÓN DEL GRUPO TÉCNICO REGIONAL DEL CONO SUR EM MEJORAMIENTO Y UTILIZACIÓN DE LOS RECURSOS FORRAGEROS DEL ÁREA TROPICAL Y SUBTROPICAL - GRUPO CAMPOS, 20., 2004, Salto. Anais... Salto: Regional Norte de la República del Uruguay, 2004. p.213-214.

MEDEIROS, R. B.; PILLAR, V. P.; REIS, J. C. L. Expansão de Eragrostis plana Nees. (Capim-Annoni-2) no Rio Grande do Sul e indicativos de controle. In: REUNIÓN DEL GRUPO TÉCNICO REGIONAL DEL CONO SUR EM MEJORAMIENTO Y UTILIZACIÓN DE LOS RECURSOS FORRAGEROS DEL ÁREA TROPICAL Y SUBTROPICAL - GRUPO CAMPOS, 20., 2004, Salto. Anais... Salto: Regional Norte de la Universidad de la República del Uruguay, 2004. p.211-212.

RADOSEVICH, S.; HOLT, J.; GHERSA, C. Weed ecology - implication for managment. New York: John Wiley Professio, 1997. 608p.

REZENDE, C. P.; PINTO, J. C.; EVANGELISTA, A. R.; SANTOS, I. P. A. Alelopatia e suas interações na formação e manejo de pastagens. Boletim Agropecuário, Universidade Federal de Lavras, Lavras, n. 54, p.1-55, 2003.

RICE, E. L. Allelopathy: an update. The Botanical Review, 
Bronx, v. 45, p.15-109, 1979.

RICE, E. L. Allelopathy. London: Academic Press, 1984. $422 \mathrm{p}$.

RIZVI, S.J.H.; RIZVI,V. Allelopathy- Basic and applied aspects. London: Chapman \& Hall, 1992. 480p.

STRECK, E. V.; KÄMPF, N.; DALMOLIN, R. S. D.; KLAMT, E.; NASCIMENTO, P. C.; SCHEIDER,P. Solos do Rio Grande do Sul. Porto Alegre: UFRGS, 2002. 107p.
STRICKLAND, R. W. Seed production and testing problems in tropical and sub-tropical pasture. Proceedings of the International Seed Testing Association, Brisbane, v.36, n.1, p.189-199, 1971.

VISSER, J,H. Root exudates of Eragrostis curvula as an ecological factor. In: INTERNATIONAL GRASSLAND CONGRESS, 9., 1966, São Paulo. Proceedings... São Paulo, 1966. p 453-455. 